\title{
Effect of Process Parameters on the Performance of Micro-EDM
}

\author{
Vasantha Prasath $\mathbf{N}^{1}$, Mohanraj $\mathbf{R}^{2}$, Nandhakumar $\mathbf{M}^{3}$ \\ ${ }^{1,2,3}$ Assistant Professor, Dept. of Mechanical Engg, GRT Institute of Engg \& Tech, Tiruttani
}

\begin{abstract}
Electrical discharge machining (EDM) is an important process in the field of micro machining. However, a number of issues remain to be solved in order to successfully implement it in an industrial environment. One of these issues is the processing time. This paper investigates the optimization of machining parameters for Material Removal Rate and over cut in micro EDM. In one case, the parameters are selected to achieve the highest material removal rate (MRR). In the other case, the lower over cut is targeted. Some of the main difficulties linked with micro EDM are caused by the high wear occurring on the electrode. The study focuses on a specific combination of electrode and workpiece material and proposes a typical method for micro EDM process.
\end{abstract}

Keywords: Electrical Discharge Machining, Orthogonal Array, Taguchi Method, S/N Ratio, 304 Stainless steel

\section{Introduction}

Electrical discharge machining (spark erosion machining) is mainly a technique used for the manufacture of a multitude of ever changing geometries very often produced as unit jobs or in small batches. The basic concepts of electrical discharge machining process is cratering out of metals affected by the sudden stoppage of the electron beam by the solid metal surface of the anode. Recently, there has been an increasing demand for micro machining due to the reduction in size and weight of technological devices. When producing micro components, it is critical to achieve high accuracy and precise dimensions. It is difficult to produce complex micro components such as micro dies made of high-hardness materials using conventional machining methods such as micro milling or micro turning.

Hence, nontraditional machining methods become more and more important. Within all the nontraditional machining methods, electrical discharge machining (EDM) is the one with the highest potential because it is not affected by mechanical properties of the work piece such as material hardness or material strength. EDM works on any conductive materials and has advantages like easy to operate and requires only simple equipments. Since there is no contact between the electrode and the work piece for EDM process, the force generated during the process is far less than traditional machining methods; therefore, the EDM can be a good candidate for miniature part machining. The EDM technique has been widely used in the aerospace industry, micro electro mechanical system, and the manufacturing of molding dies and biomedical equipments. However, when kerosene is used as the dielectric fluid in the EDM process, with the generated high heat, tars and carbon will be decomposed from kerosene. Due to the small gap between the electrode and the work piece, the carbon and debris cannot be removed easily; which will result in an unstable discharge state such as concentrated discharge or secondary discharge. As a result, a reduced material removal rate and a worsened surface roughness will be observed. Experiments have been carried out to analyze the influence of some of the ascendant process parameters such as gap voltage, gap current, pulse on time and duty factor on the material removal rate (MRR) and over cut during micromachining through the EDM setup.

The vibration-EDM is realized by the vibrating worktable designed, which is employed in the micro-punching machine we had already developed. It is found that larger feed and better surface finish can be achieved in micro-EDM with vibration machining. Circular and noncircular microelectrodes of diameter below $200 \mu \mathrm{m}$ were fabricated with vibration-EDM and the setup of u-axis. Experiments to punch micro holes of diameter $200 \mu \mathrm{m}$ on SUS304 stainless steel and brass strips were carried out. Mass punching of micro-holes on brass strip was performed successfully, using the automatic feeding system developed. The capability of micro-punching and effects of parameters on the quality of punched micro hole.[1]

The pulse discriminating and control system identifies four major gap states classified as open circuit, normal spark, are discharge and short circuit based on the characteristics of gap voltage waveform. The effect of pulse interval, machining federate and work piece thickness on the variations of the proportion of normal spark, arc discharge and short circuit in the total sparks. It is found that a long pulse interval results in an increase of the short ratio under a constant federate machining condition. A high machining feed rate or an increase of work piece height results in an increase of the short ratio. To achieve the stability of the machining operation, a control strategy is proposed by regulating the pulse interval of each spark in real-time according to the identified gap states. Experimental results indicate that the developed pulse discriminating and control system can significantly reduce the arc discharge and short sparking frequency as well as achieve stable machining under the condition where the instability of machining operation is prone to occur. [3]

The experimental research on the machining of sintered diamond (SD) by electrical discharge machining (EDM).Experiments were carried out with four types of SD, composed of $1,3,10$, and $20 \mu \mathrm{m}$ diameter diamond particles. Tungsten carbide alloy was also tested for comparison. Basic characteristics of micro-EDM were investigated by machining through-holes and trenches in SD 


\section{International Journal of Science and Research (IJSR) \\ ISSN (Online): 2319-7064}

Index Copernicus Value (2015): 78.96 | Impact Factor (2015): 6.391

plates. Although in some cases unstable machining status was observed, it was found that SD has machining characteristics basically similar to those of tungsten carbide alloy. Machined surfaces were observed in the experiment of machining trenches. The surface roughness of SDs was found to be sufficiently good for micro mold applications and the surface property of SDs with large diamond particles was quite different from that of metals.[5]

\section{Experiment Description}

The process parameters like gap voltage, gap current, pulse on time and duty factor were greatly influence on the $\mu$ EDM performance. In EDM, polarity - work piece (+), tool (-). So, that the tool wear will be low. Machining time for EDM process is set to 15 minutes. The working medium of the $\mu$-EDM is dielectric (EDM oil). The inter electrode gap control plays a major role. If the inter electrode gap is controlled in the range of $15-20 \mu \mathrm{m}$. The gap is very small; contamination can cause a deposition to be formed on the tool, so that the work piece no longer dissolved uniformly. This problem can be largely avoided by applying a pulsed DC voltage instead of a continuous one. The characteristics of the tool desired for rigid EDM has high electric, thermal conductivity and high stiffness. Suitable metal for the microtool is tungsten carbide.

\section{1 $\mu$-EDM Setup}

The influence of the ascendant process characteristics, a well planned programme was considered for the indigenous development of the $\mu$-EDM set-up. $\mu$-EDM set-up consists of various sub-components, e.g. power supply unit, machining chamber, tool post and holding device, tool feed system etc. As shown in Figure.1. Presents a schematic view of the Electrical Discharge Micro Machine. Electrical discharge machining process are influenced by the number of parameters such as Voltage, current, pulse on time and so on. The experimental setup provides all the facilities to control the process parameters to study their effect on machining. The whole experimental setup of Electrical discharge machining setup is divided in to various sub units.

\subsection{Power supply unit}

The power supply is given by means of variable DC supply. Experiments are carried out with four different voltage settings such as $5-6.5 \mathrm{~V}$. The tool is given negative charge which acts as cathode. The work piece is given positive charge which acts as anode.

\subsection{Machining chamber}

The machining takes place in the machining chamber. The machining tank consists of inlet and outlet for the dielectric flow. The machining chamber is internally painted with corrosion resistant paint, in order to avoid corrosion due to use of dielectric. A work piece holding table is placed inside the machining chamber to hold the work piece. The machining chamber is designed to maintain a constant level of dielectric in order to enhance the machining process.

\subsection{Tool post and holding device}

The tool post is a rigid vertical member which is connected with main body of the machine. The vertical and horizontal frame of the tool post is provided with screw nut arrangement in order to obtain the tool movement throughout the machining chamber. This movement of the tool is obtained by rotating the separate hand wheel arrangement provided for the both axis. The tool holder is fixed on the bottom of the tool post. The tool holder is a three jaw chuck which can be opened and closed by means of a key. The tool holder is capable to hold even very small diameter tool. The diameter of the tool which is used for the electrical discharge micro machining are 300 micro meter. The chuck is selected to hold effectively even very small diameter like this $300 \mu \mathrm{m}$.

\subsection{Tool feed system}

In electrical discharge machining process the tool feed system is very important one, because the gap between the tool and work piece must be maintained at optimal value for obtaining the effecting machining process. The gap between the tool and work piece is increased while machining takes place because of the material removal from the work piece. The tool should be held in the machining zone for effective machining process. For that feed is given to the tool by means of a

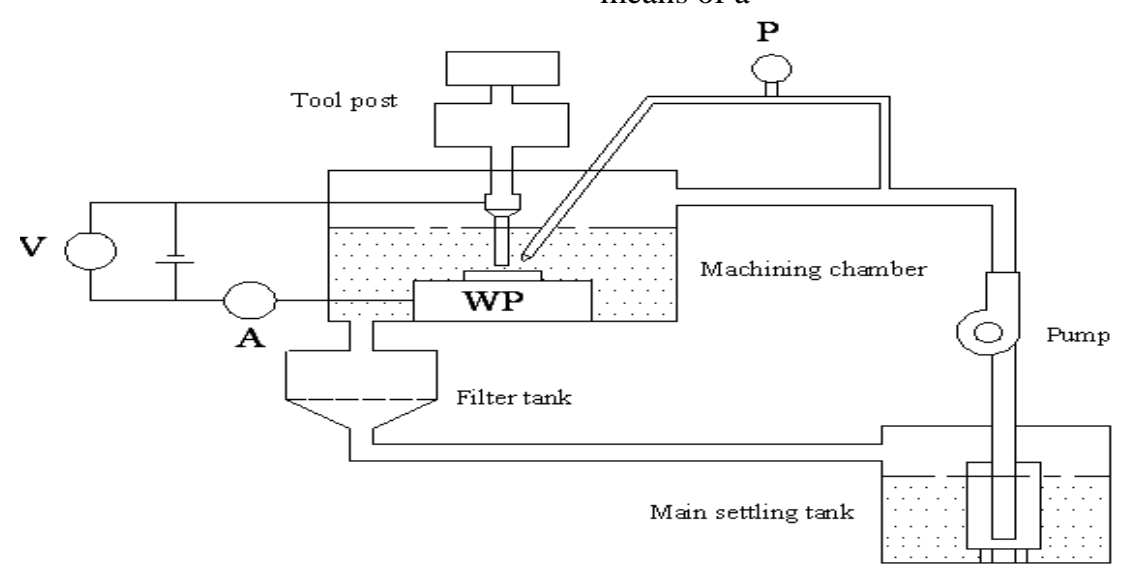

V-Voltmeter, A- Ammeter, P-Pressure Gauge, WP-Workpiece

Figure 1: Electrical Discharge Micro Machine 


\section{International Journal of Science and Research (IJSR) \\ ISSN (Online): 2319-7064}

Index Copernicus Value (2015): 78.96 | Impact Factor (2015): 6.391

closed loop control system. The control system senses the gap voltage. According to the gap voltage the control system gives the signal to move the tool upwards or downwards. Thus the tool feed control system is used to maintain a small machining gap between the tool and work piece.

\subsection{Dielectric flow system}

The dielectric is made to flow between the tool and work piece. The main flow of dielectric starts from main settling tank. The main settling tank is used to store the dielectric. The dielectric from the main settling tank is pumped to the machining chamber by means of an electrical pump. The dielectric from the machining chamber is then made to flow to the filtration tank. Then the filtered dielectric flows back to the main settling tank. The filtration tank consist a filter wire mesh with very small diameter holes. The dielectric from the machining chamber with the debris flows to the filtration tank. The debris from the machining chamber is filtered by the wire mesh. Then the dielectric which is free from debris flows to the main settling tank. The suction pipe of the electrical pump is connected with a stainless steel strainer. For machining, the dielectric is re circulated again and again. The other purpose of the dielectric recirculation is to dissipate the heat away from the machining zone. High temperature results in boiling of the dielectric. This reduces the effectiveness of the machining process. So the temperature in the machining zone should be kept at optimal value. The dielectric recirculation is used to maintain the dielectric temperature in the machining zone at optimal value. The flow system makes the contaminated dielectric to flow away from the machining zone and makes fresh dielectric to flow into the machining gap.

\subsection{Flushing unit}

Apart from the main dielectric flow system a flushing system is made use to make the dielectric to flow in the machining gap. The dielectric is flushed between the tool and work piece with the help of flexible nozzle pipe. The flushing pressure is kept very low because in the micromachining the tool diameter is very small, high pressure will make the tool to oscillate. The oscillation of tool results the inaccurate shape. In order to avoid this, the flushing pressure is kept at small value. The flushing of the dielectric in the machining gap results in effective removal of debris and hence the material removal rate is increased.

\section{Planning for Experimental Analysis}

Table. 1 shows that various process parameters and their levels of $\mu$-EDM

Table 1: Process Parameters and their levels of $\mu$-EDM

\begin{tabular}{|c|c|c|c|c|}
\hline Control Parameters & L 1 & L 2 & L 3 & L4 \\
\hline Gap Voltage $(\mathrm{V})$ & 20 & 30 & 40 & 50 \\
\hline Gap Current $(\mathrm{A})$ & 0.2 & 0.3 & 0.4 & 0.5 \\
\hline Pulse on time $(\mu \mathrm{s})$ & 20 & 30 & 40 & 50 \\
\hline Duty Factor & 0.5 & 0.55 & 0.6 & 0.65 \\
\hline
\end{tabular}

Table 2 shows the L 16 orthogonal array for Electrical discharge Micromachining of Stainless Steel
Table 2: L 16 Orthogonal array

\begin{tabular}{|c|c|c|c|c|}
\hline S.No & Voltage & Current & Pulse on time & Duty factor \\
\hline 1 & 1 & 1 & 1 & 1 \\
\hline 2 & 1 & 2 & 2 & 2 \\
\hline 3 & 1 & 3 & 3 & 3 \\
\hline 4 & 1 & 4 & 4 & 4 \\
\hline 5 & 2 & 1 & 2 & 3 \\
\hline 6 & 2 & 2 & 1 & 4 \\
\hline 7 & 2 & 3 & 4 & 1 \\
\hline 8 & 2 & 4 & 3 & 2 \\
\hline 9 & 3 & 1 & 3 & 4 \\
\hline 10 & 3 & 2 & 4 & 3 \\
\hline 11 & 3 & 3 & 1 & 2 \\
\hline 12 & 3 & 4 & 2 & 1 \\
\hline 13 & 4 & 1 & 4 & 2 \\
\hline 14 & 4 & 2 & 3 & 1 \\
\hline 15 & 4 & 3 & 2 & 4 \\
\hline 16 & 4 & 4 & 1 & 3 \\
\hline
\end{tabular}

To analyze the control of the desired performance characteristics of the process parameters of the electrical discharge machining system, a scheme was designed so as to properly utilize the $\mu$-EDM set-up. The micro-tools, made up of tungsten carbide wires with a diameter of $300 \mu \mathrm{m}$, were used for the experiments. The test work piece specimens were $20 \mathrm{~mm} \times 20 \mathrm{~mm} \times 0.6 \mathrm{~mm}$ stainless steel (430) plates. The working medium for electrical discharge machining process is dielectric. In 20 to $50 \mathrm{~V}$ was used for experimentation. In $\mu$-EDM, pulse on time range of 20 to 50 $\mu \mathrm{s}$.

The variation of material removal rate (MRR) and Over cut were observed for the various ascendant electrical discharge machining parameters such as applied voltage, gap current and pulse on time. In $\mu$-EDM, the range of gap voltage, gap current, pulse on time and duty factor were chosen such as 20-50 V, 0.2-0.5 A, 20-50 $\mu$ s and 0.5-0.65, respectively. Initial and final weights of the jobs were taken by a precision electronic weighing machine. MRR was calculated as the material removed, i.e. the difference of initial and final weight per unit machining time. Radial over cut of the machined micro-hole had been considered as machining accuracy criteria. The hole diameters were measured with the help of a metrology microscope and tool diameters with electronic digital vernier scale with a least count of 0.001 $\mathrm{mm}$. The condition of machined micro-holes was observed with the help of micrographs obtained through the Metallurgical microscope.

Radial overcut $(\mathrm{mm})=($ Hole diameter - Tool diameter $) / 2$ $\operatorname{MRR}(\mathrm{mg} / \mathrm{min}) \quad=($ Initial weight - Final weight $) /$ Machining time

\section{Experimental Results and Discussion}

\subsection{Effect of pulse on time on MRR}

As shown in Figure 2, the material removal rate increases with pulse on time at a distinct machining condition, i.e. gap voltage of $30 \mathrm{~V}$, gap current of $0.4 \mathrm{~A}$ and duty factor, 0.6. Increase in pulse on time will increase the machining time. Increase in pulse on time implies that more time has been allowed to machine the work piece. In other words, with the increase of pulse on time, average current density increases 


\section{International Journal of Science and Research (IJSR) \\ ISSN (Online): 2319-7064}

Index Copernicus Value (2015): 78.96 | Impact Factor (2015): 6.391

which leads to the increase of dissolution efficiency. Figure 3 shows a micrograph of a micro-hole produced by $\mu$-EDM at a particular parametric combination for maximum MRR, i.e. gap voltage of $30 \mathrm{~V}$, pulse on time of $50 \mu \mathrm{s}$, duty factor of 0.6 and gap current of $0.4 \mathrm{~A}$.

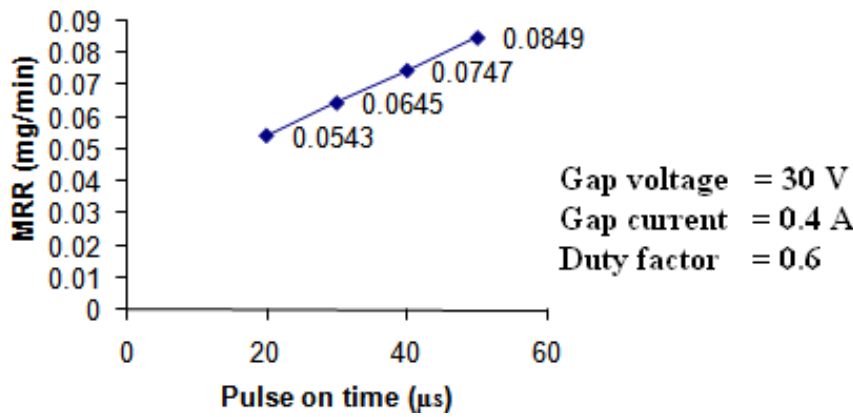

Figure 2: Variation of MRR with pulse on time

With a given pulse duration, the energy density increases as the discharge current increases. On the other hand, when the discharge current is too large the explosive energy is huge, and the discharge spark is drastic. The micro hole is irregular in shape, because increasing the pulse on time more time allowed machining the workpiece.

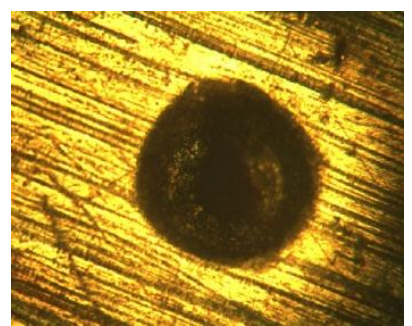

Figure 3: Micrograph of machined hole at a particular parametric machining condition, i.e., $30 \mathrm{~V}, 0.4 \mathrm{~A}, 50 \mu$ s and 0.6

\subsection{Effect of duty factor on MRR}

As shown in Figure 4, the material removal rate increases with duty factor at a distinct machining condition, i.e. gap voltage of $30 \mathrm{~V}$, gap current of $0.4 \mathrm{~A}$ and pulse on time, $20 \mu \mathrm{s}$. Duty factor increases, number of machining pulses increases.

Duty factor $=$ on time $/$ (on time + off time)

Frequency $=1 /$ (on time + off time $)$

For example, on time $=10 \mu \mathrm{s}$, duty factor $=0.5$, off time $=$ $10 \mu \mathrm{s}$

Frequency $=1 /\left(20 \times 10^{-6}\right)=50 \mathrm{kHz}$

On time increases, frequency also increases. Hence, MRR also increases. Figure 5 shows a micrograph of a micro-hole produced by $\mu-E D M$ at a particular parametric combination for maximum MRR, i.e. gap voltage of $30 \mathrm{~V}$, pulse on time of $20 \mu \mathrm{s}$, duty factor of 0.65 and gap current of $0.4 \mathrm{~A}$.

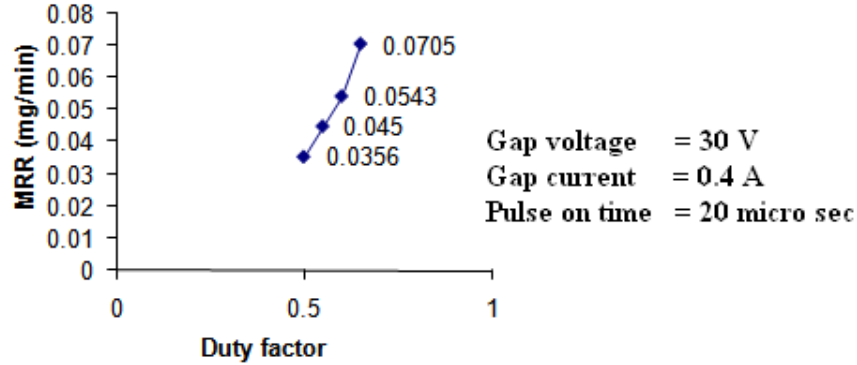

Figure 4: Variation of MRR with duty factor

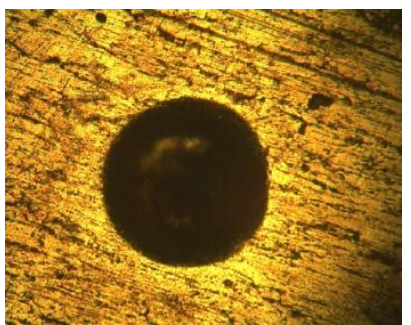

Figure 5: Micrograph of machined hole at a particular parametric machining condition, i.e., $30 \mathrm{~V}, 0.4 \mathrm{~A}, 20 \mu \mathrm{s}$ and 0.65

\subsection{Effect of gap voltage on over cut and tool wear}

As shown in Figure 6, the over cut increases with voltage at a distinct machining condition, i.e. gap current of $0.4 \mathrm{~A}$, pulse on time of $20 \mu \mathrm{s}$ and duty factor, 0.6. Rise in gap voltage means gap between tool and workpiece is more. So, spill over of electrons will be more. Hence, the overcut is high.

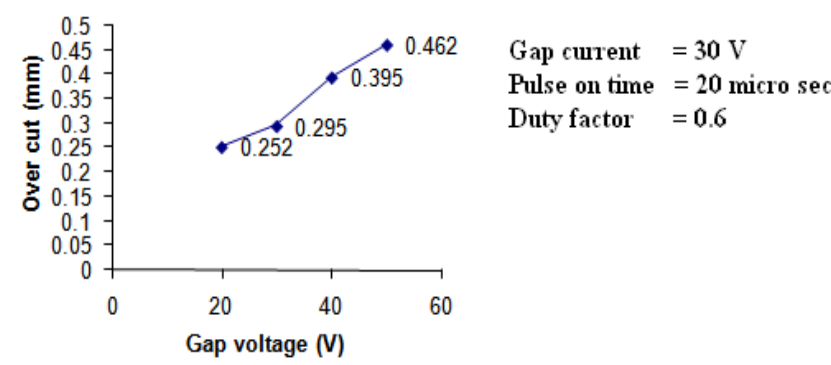

Figure 6: Variation of over cut with gap voltage

As shown in Figure 7, the tool wear increases with voltage at a distinct machining condition, i.e. gap current of $0.4 \mathrm{~A}$, pulse on time of $20 \mu \mathrm{s}$ and duty factor, 0.6. Electrode wear is not a major problem for micro-EDM, apart from the fact that a high rate of tool wear might cause more frequent breaks. Figure 8 shows a micrograph of a micro-hole produced by $\mu$-EDM at a particular parametric combination for over cut and tool wear, i.e. gap current of $0.4 \mathrm{~A}$, pulse on time of 20 $\mu \mathrm{s}$, duty factor of 0.6 and machining voltage of $50 \mathrm{~V}$.

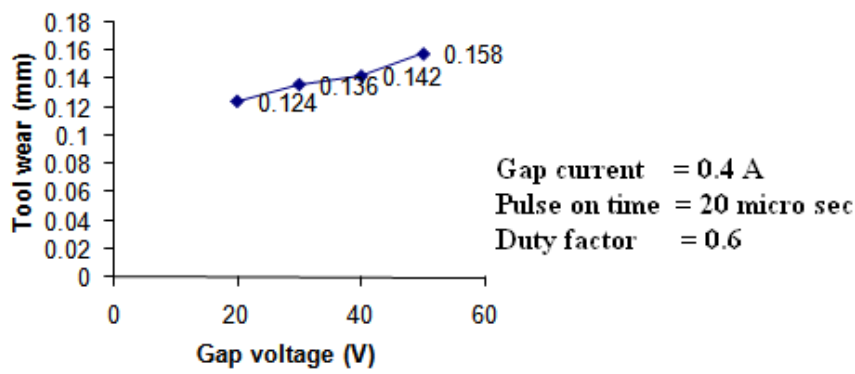

Figure 7: Variation of tool wear with gap voltage 


\section{International Journal of Science and Research (IJSR) \\ ISSN (Online): 2319-7064}

Index Copernicus Value (2015): 78.96 | Impact Factor (2015): 6.391

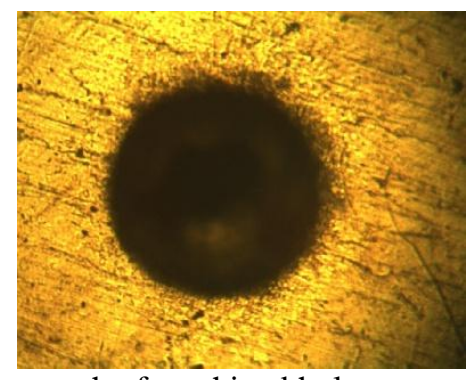

Figure 8: Micrograph of machined hole at a particular parametric machining condition, i.e., $50 \mathrm{~V}, 0.4 \mathrm{~A}, 20 \mu \mathrm{s}$ and 0.6

At higher voltage, gas bubbles break down resulting in the occurrence of micro sparking. This sparking causes uncontrolled material removal from the workpiece and finally larger overcut is the consequent result.

\subsection{Effect of gap current on over cut and tool wear}

As shown in Figure 9, the over cut increases with gap current at a distinct machining condition, i.e. gap voltage of $30 \mathrm{~V}$, pulse on time of $20 \mu \mathrm{s}$ and duty factor, 0.6. Current increases, intensity of the plasma increases. Crater size also increases. Crater- the depletion created by a single spark or pulse. Hence, the over cut also increases.

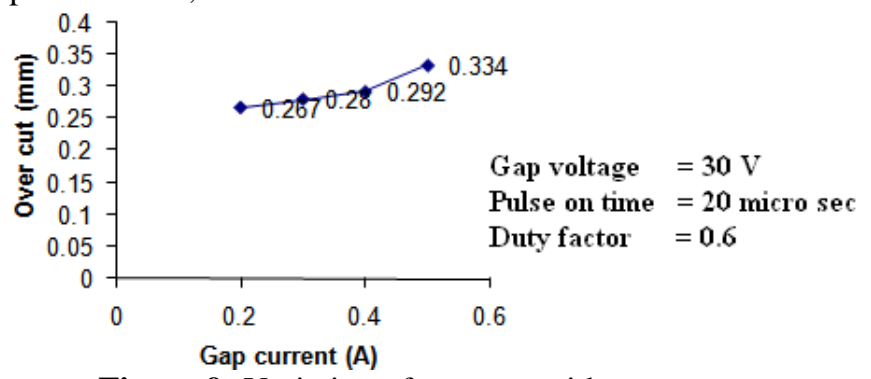

Figure 9: Variation of over cut with gap current

As shown in Figure 10, the tool wear increases with gap current at a distinct machining condition, i.e. gap voltage of $30 \mathrm{~V}$, pulse on time of $20 \mu \mathrm{s}$ and duty factor, 0.6. Figure 11 shows a micrograph of a micro-hole produced by $\mu$-EDM at a particular parametric combination for over cut and tool wear, i.e. gap current of $0.5 \mathrm{~A}$, pulse on time of $20 \mu \mathrm{s}$, duty factor of 0.6 and machining voltage of $30 \mathrm{~V}$. If the gap current increases, the tool wear also increases. But, the gap voltage will be lower means the tool wear slightly increases. The micro hole is almost circular depending upon the voltage, current and duty factor.

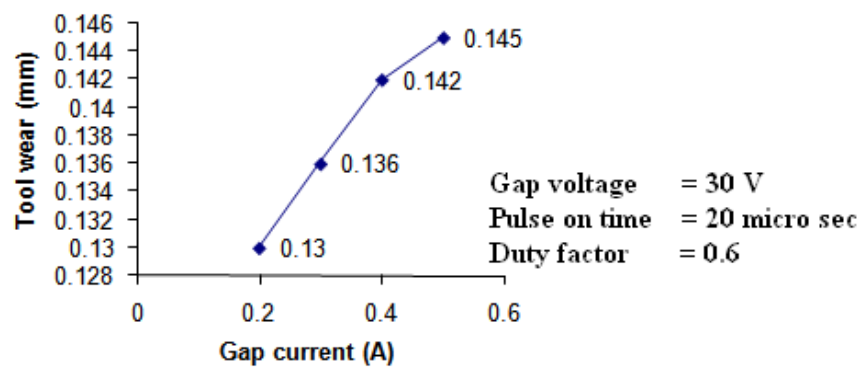

Figure 10: Variation of tool wear with gap Current

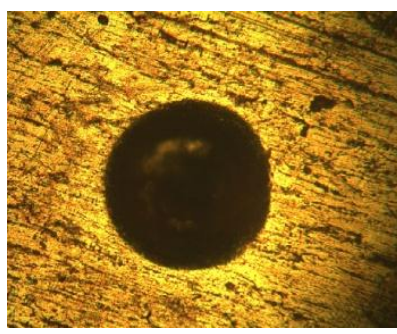

Figure 11: Micrograph of machined hole at a particular parametric machining condition, i.e., $30 \mathrm{~V}, 0.5 \mathrm{~A}, 20 \mu \mathrm{s}$ and 0.6

\subsection{Effect of pulse on time on over cut and tool wear}

As shown in Figure 12, the over cut increases with pulse on time at a distinct machining condition, i.e. gap voltage of 30 $\mathrm{V}$, gap current of $0.4 \mathrm{~A}$ and duty factor, 0.6. On time increases, plasma radius increases. Hence, the crater size increases. Increase the pulse on time, at that time more spark will be produced. Due to the sparks, the removal of debris will be low. Hence, the overcut increases.

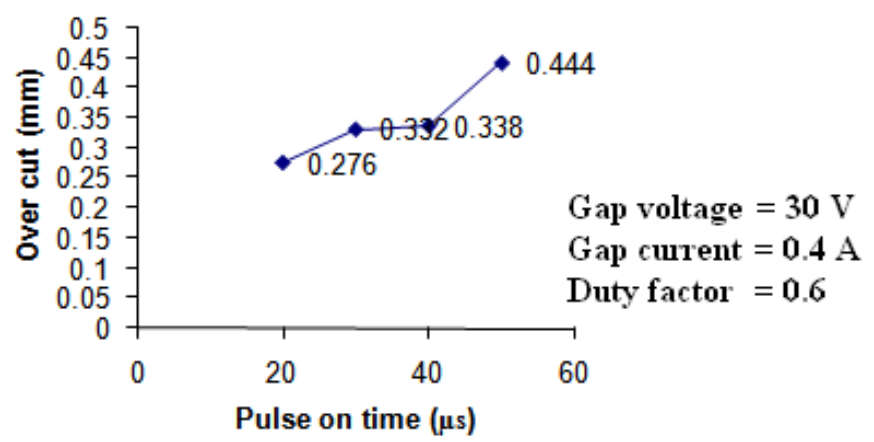

Figure 12: Variation of over cut with pulse on time

As shown in Figure 13, the tool wear increases with pulse on time at a distinct machining condition, i.e. gap voltage of 30 $\mathrm{V}$, gap current of $0.4 \mathrm{~A}$ and duty factor, 0.6.The pulse on time increases, at that time tool wear also increases. Depending upon the on time tool edges are damaged and then wear rate should be very high.

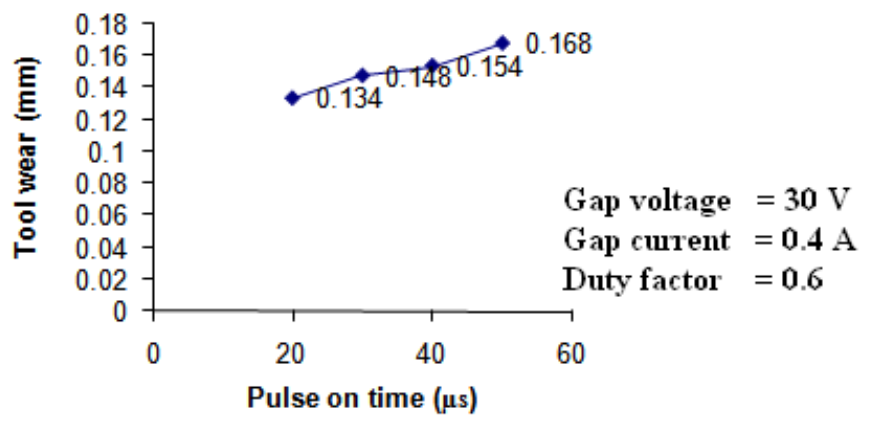

Figure 13: Variation of tool wear with pulse on time

Figure 14 shows a micrograph of a micro-hole produced by $\mu$-EDM at a particular parametric combination for over cut and tool wear, i.e. gap current of $0.4 \mathrm{~A}$, pulse on time of 50 $\mu \mathrm{s}$, duty factor of 0.6 and gap voltage of $30 \mathrm{~V}$. 


\section{International Journal of Science and Research (IJSR) \\ ISSN (Online): 2319-7064}

Index Copernicus Value (2015): 78.96 | Impact Factor (2015): 6.391

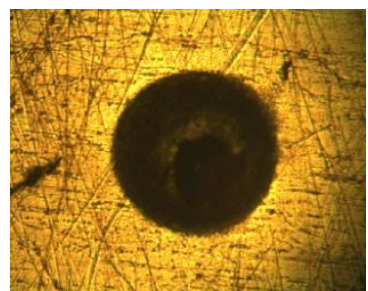

Figure 14: Micrograph of machined hole at a particular parametric machining condition, i.e., $30 \mathrm{~V}, 0.4 \mathrm{~A}, 50 \mu \mathrm{s}$ and 0.6

\subsection{Effect of duty factor on over cut and tool wear}

As shown in Figure 15, the over cut increases with duty factor at a distinct machining condition, i.e. gap voltage of

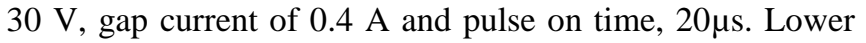
rate of duty factor, it provides more off time. So, easy removal of debris. Hence will take place less occurrence of arcing which leads to low overcut. As shown in Figure 16, the tool wear increases with duty factor at a distinct machining condition, i.e. gap voltage of $30 \mathrm{~V}$, gap current of

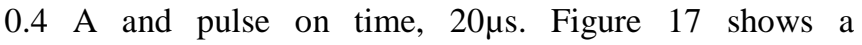
micrograph of a micro-hole produced by $\mu$-EDM at a particular parametric combination for over cut and tool wear, i.e. gap current of $0.4 \mathrm{~A}$, pulse on time of $20 \mu \mathrm{s}$, duty factor of 0.65 and gap voltage of $30 \mathrm{~V}$.

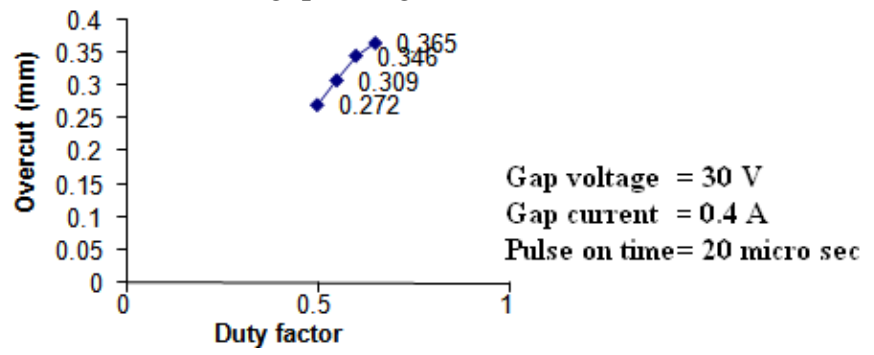

Figure 15: Variation of over cut with duty factor

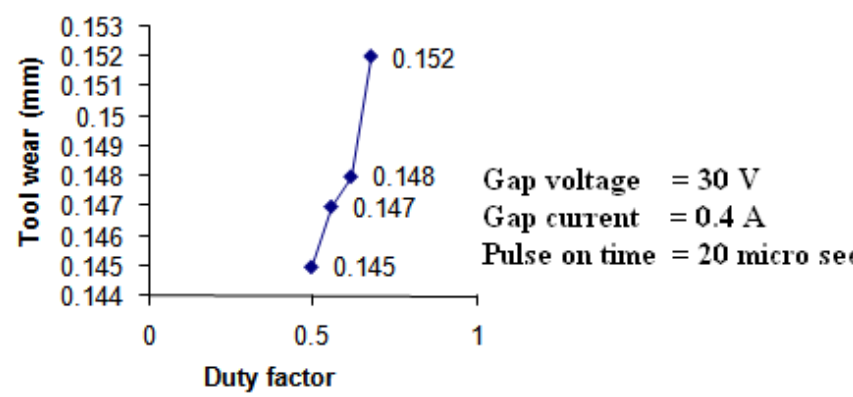

Figure 16: Variation of tool wear with duty factor

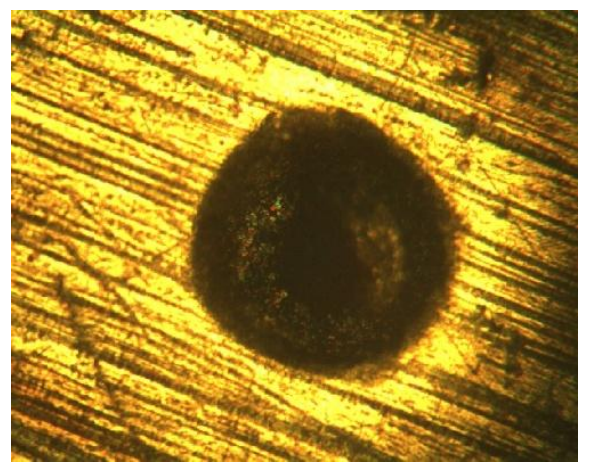

Figure 17: Micrograph of machined hole at a particular parametric machining condition, i.e., $30 \mathrm{~V}, 0.4 \mathrm{~A}, 20 \mu \mathrm{s}$ and 0.65

\section{Conclusion}

This paper mainly consists of various activities to show the influence of different ascendant process parameters of $\mu$ EDM on the machining rate and accuracy. In micro-EDM, the process parameters like gap voltage, gap current, pulse on time and duty factor have been considered to analyze the influence on MRR and overcut. A gap voltage range of $30-$ $40 \mathrm{~V}$ gives an appreciable amount of MRR and the most effective zone of pulse on time, gap current and duty factor can be considered as $20-30 \mu \mathrm{s}, 0.2-0.3 \mathrm{~A}$ and $0.5-0.6$, respectively, which gives an appreciable amount of MRR as well as lesser overcut. The $\mu$-EDM gives the higher material removal rate. Preferably $\mu-E D M$ is the best process, because quick machining and to produce complex shapes. In other words electrical discharge machining can be used as an effective micromachining technique by overcoming these shortcomings, identified by the present paper.

\section{References}

[1] Gwo-Lianq Chern, Ying-Jeng Engin Wu, Jyun-Cheng Cheng, Jian-Cheng Yao, 2007, "Study on burr formation in micro-machining using micro-tools fabricated by micro-EDM", Precision Engineering, 31, 122-129.

[2] Gwo-Lianq Chern, Sen-De Wang, 2007, "Punching of non circular micro-holes and development of microforming", Precision Engineering, 31, 210-297.

[3] Mu-Tian Yan, Hsing-Tsung Chien, 2007, "Monitoring and control of the micro wire-EDM process", International Journal of Machine Tools \& Manufacture, 47, 148-157.

[4] Mohan Sen and Shan H.S, 2005, "A review of electrochemical macro- to micro-hole drilling processes", International Journal of Machine Tools \& Manufacture, 45, 137-152.

[5] Nakaoku.H, Masuzawa.T, Fujino.M, 2007, "Micro-EDM of sintered diamond", Journal of Materials Processing Technology, 187-188, 274-278

[6] Pham.D.T, Dimov.S.S, Bigot.S, Ivanov.A, Popov.K, 2004, "Micro-EDM- recent developments and research issues", Journal of Materials Processing Technology, $149,50-57$.

[7] Takahata.K, Aoki.S and Sato.T, 1996, "Fine Surface Finishing Method for 3-D Structures", IEEE, 0-78032985-6, 73-78.

[8] Yao-Yang Tsai, Takahisa Masuzawa, 2004, "An index to evaluate the wear resistance of the electrode in microEDM", Journal of Materials Processing Technology, 149, 304-309. 